\title{
215 弾性流体潤滑理論に関する研究
}

（第 1 報 : Reynolds 式についての運動学・力学的検討）

On the Elasto-Hydrostatic Lubrication Theory (Part 1: Mechanical Discussions on the Reynolds Equation)

○沢田孚夫 (東京農工大)

雪 真人 (東京農工大・院)

Takao SAWADA, Tokyo University of Agriculture and Technology, Naka-cho, Koganei-shi; Tokyo

Masato YUKI, Tokyo University of Agriculture and Technology

The classical problem "Pressure Spike" has not been cleared by the conventional numerical method. Here, EHL theory is discussed mechanically by beginning with the formulation of one dimensional fluid flow and deriving the analytical solutions of the Reynolds equation. And the process to program the computer code for the numerical analysis is presented. It is found that the pressure peak may be caused by the errors of the numerical processes. In the result, the pressure spike cannot be obtained by the numerical solution of the Reynolds equation.

Key Words: Pressure spike, Analytical solution, Reynolds equation, one dimensional flow

\section{1.はじめに}

Reynolds の1 次元流机を用いた従来の EHL 理論によって, 圧力突起 (Fig. 1)が生じるという多数の報告がある. 本報では, 振り返って Reynolds の式, その数值解法, 及び解の特徴につ いて述べ, 圧力突起は生じないことを示す.

\section{Reynolds の式の検討}

$\mathrm{x} \cdot \mathrm{z}$ 平面での流れで潤滑油を $\mathrm{x}$ 方向の 1 方向定常粘性流れ u とする. $\mathrm{y} ; \mathrm{z}$ 方向の流速の成分は $\mathrm{v}(\mathrm{x}, \mathrm{z}) \dot{\mathrm{j}} \mathrm{w}(\mathrm{x}, \mathrm{z})=\mathbf{0}$.

連続の式より流速成分 $\mathrm{u}(\mathrm{x}, \mathrm{z})$ は $\mathrm{u}(\mathrm{z})$ となり， $\mathrm{x}$ 方向の流線に 沿って一定となる.このため, せん断応力は $\mathrm{z}$ のみの関数と なり, $\mathrm{z}$ 方向のせん断応力は無視される.

$$
\tau_{z x}(z)=\mu(d u(z) / d z)
$$

1 次元流れの微小要素についてつりあい式は;

$$
\frac{d p(x)}{d x}=\frac{d \tau_{z x}(z)}{d z}
$$

式(1)より

$$
\frac{d p(x)}{d x}=\mu \frac{d^{2} u(z)}{d z^{2}}
$$

末知数 $\mathrm{p}(\mathrm{x})$ と $\mathrm{u}(\mathrm{z})$ は 2 個，式は 1 個なので, 解くことはでき ない.

そこで式（3）に流量一定の制約条件を加える．流路の一 方が速度 V·を持つとすると，境界条件は，

$$
\mathrm{z}=0 \text { で } \mathrm{u}=0, \quad \mathrm{z}=\mathrm{h}(\mathrm{x}) \text { で } \mathrm{u}(\mathrm{h})=\mathrm{V}=\text { 一定 }
$$
式 (3) は,

$$
u(z)=\frac{1}{2 \mu}\left(z^{2}-h(x) z\right) \frac{d p(x)}{d x}+\frac{V}{h(x)} z
$$

単位幅あたりの流量 q 0 を考える. 式(5)を用いて，

$$
q_{0}=\int_{0}^{h} u(z) b d z=-\frac{h^{3}(x)}{12 \mu} \frac{d p(x)}{d x}+\frac{V h(x)}{2}
$$

$\mathrm{q}_{0}=\mathrm{Vh}_{\mathrm{m}} / 2$ とおくと $\mathrm{h}_{\mathrm{m}}$ の意味が明確でなく，物理的な意味合 いが薄れる. この結果 Reynolds 式が導かれる.

$$
\frac{d p(x)}{d x}=\frac{6 \mu V}{h(x)^{3}}\left(h(x)-h_{m}\right)
$$

\section{3. 解析解}

流体の出入口の高さを $\mathrm{h}_{2}, \mathrm{~h}_{1}$, その間の流路長さを $1,2 つ$. の壁は直線とし，圧力の境界条件（出入口で圧力 0 ）とする と, 積分定数の $\mathrm{hm}$ は次のように求めることができる.

$$
h_{m}=\frac{2 h_{1} h_{2}}{h_{1}+h_{2}}
$$

これは調和平均であるが，物理的には定まらない。解は

$$
p=6 \mu V l\left(\frac{h_{1}-h_{2}}{h_{1}+h_{2}}\right) \frac{[l-x] x}{\left[h_{1} l-\left(h_{1}-h_{2}\right) x\right]^{2}}
$$

これから解析的に求める方法では, 圧力突起を生じさせる要 因は見当たらない。

Fig.2 の半径 r の円板モデルについて, 流体膜厚さは

$$
h(x)=h_{0}+\frac{x^{2}}{2 r}
$$

流体入り口で圧力を 0 ，壁の一方が一定速度 V、で動くとき， 圧力の式は次のように求めることができる.

$$
p(x)=12 \mu V r\left[\frac{-h_{m} r}{c_{1}\left(x^{2}+c_{1}\right)^{2}} x+\frac{2 c_{1}-3 h_{m} r}{2 c_{1}^{2}\left(x^{2}+c_{1}\right)} x+\frac{2 c_{1}-3 h_{m} r}{2 c_{1}^{2} \sqrt{c_{1}}} \tan ^{-1} \frac{x}{\sqrt{c_{1}}}\right]
$$

ここで, $\mathrm{c}_{1}=2 \mathrm{rh} 0, \mathrm{c}_{2}=\mathrm{a}^{2}+\mathrm{c}_{1}$ とおくと $\mathrm{hm}$ は

$$
h_{m}=\frac{2}{r} \frac{a c_{1} c_{2} \sqrt{c_{1}}+c_{1} c_{2}^{2} \tan ^{-1}\left(a / \sqrt{c_{1}}\right)}{2 a c_{1} \sqrt{c_{1}}+3 a c_{2} \sqrt{c_{1}}+3 c_{2}{ }^{2} \tan ^{-1}\left(a / \sqrt{c_{1}}\right)}
$$

ここでも圧力 $\mathrm{p}$ には圧力突起を起こさせる要因はない.

\section{4. 数值解法}

潤滑油が次の粘性を示すとする.

$$
\mu=\mu_{0} \exp (\kappa p): \mu_{0}, \kappa=\text { 定数 }
$$

この場合, つりあい式(7)は非線形となるが, 解は連続量なの で鋭い圧力スパイクの原因にはならない.

弾性円板との境界面は変位し, 膜厚 $\mathrm{h}(\mathrm{x})$ は式(10)から,

$$
h(x)=h_{0}+\frac{x^{2}}{2 R}-\frac{2}{\pi E} \int_{s_{l}}^{s_{2}} p(s) \ln (x-s) d s
$$

第 3 項を次のように離散化する。”

$$
h\left(x_{i}, p_{j}\right)=h_{0}+\frac{\dot{x}_{i}^{2}}{2 R}-\frac{2}{\pi E} \sum_{j=1}^{n} p\left(s_{j}\right) \ln \left(\ddot{x}_{i}-s_{j}\right) \cdot \Delta s
$$

$\mathrm{h}(\mathrm{x})$ は $\mathrm{p}(\mathrm{x})$ の関数なので, 未知数は $\mathrm{p}$ の 1 . 個に対し式は式(7) の 1 個である.これを Newton- Raphson 法で解く.

$$
f\left(x_{i}, p_{j}\right)=\left(h\left(x_{i}, p_{j}\right)\right)^{3} \cdot d p / d x-6 \mu V\left(h\left(x_{i}, p_{j}\right)-h_{m}\right)=0
$$

関数 $\mathrm{f}\left(\mathrm{x}_{\mathrm{i}}, \mathrm{p}_{\mathrm{j}}\right), \mathrm{h}\left(\mathrm{x}_{\mathrm{i}}, \mathrm{p}_{\mathrm{j}}\right)$ の偏微分は次のようになる.

$$
\begin{aligned}
& \frac{\partial f\left(x_{i}, p_{j}\right)}{\partial p_{j}}=3\left(h\left(x_{i}, p_{j}\right)\right)^{2} \frac{\partial h\left(x_{i}, p_{j}\right)}{\partial p_{j}} \frac{d p}{d x} \\
& +h\left(x_{i}, p_{j}\right)^{3} \frac{\partial}{\partial p_{j}}\left(\frac{d p}{d x}\right)-6 V\left(h\left(x_{i}, p_{j}\right)-h_{m}\right) \frac{d \partial \mu}{d p_{j}} \\
& -6 \mu V \frac{\partial h\left(x_{i}, p_{j}\right)}{\partial p_{j}} \\
& \frac{\partial}{\partial p_{i}}\left(\frac{d p}{d x}\right) \cong \frac{p_{i+1}-2 p_{i}+p_{i-1}}{\Delta x\left(p_{i+1}-p_{i}\right)} \\
& \frac{\partial h\left(x_{i}, p_{j}\right)}{\partial p_{i}}=-\frac{2}{\pi E} \ln \left(x_{i}-s_{j}\right) \cdot \Delta s
\end{aligned}
$$


( 17 ( 7 )

圧力の境界条件を $\mathrm{p}_{1}=0, \mathrm{p}_{\mathrm{n}}=0$ とおき, $\mathrm{h}_{\mathrm{m}}$ は適当に与える. このとき式(17)は, $\mathrm{n}-2$ 個の未知数 $\mathrm{p}\left(\mathrm{x}_{i}\right)$ を持つ方程式 $\mathrm{n} \cdot 2$ 個が成り立つ.

$\left[\begin{array}{l}\partial f_{2} / \partial p_{1} \partial f_{2} / \partial p_{2} \ldots \partial f_{2} / \partial p_{n-1} \\ \partial f_{3} / \partial p_{1} \partial f_{3} / \partial p_{2} \cdots \partial f_{3} / \partial p_{n-2} \\ \cdots \cdots \cdots \cdots \cdots \cdots \cdots \cdots \\ \partial f_{n-1} / \partial p_{1} \partial f_{n-1} / \partial p_{2} \ldots \partial f_{n-1} / \partial p_{n-1}\end{array}\right] \cdot\left\{\begin{array}{l}\Delta p_{2} \\ \Delta p_{3} \\ \vdots \\ \Delta p_{n-1}\end{array}\right\}=\left\{\begin{array}{l}-f_{2} \\ -f_{3} \\ \vdots \\ -f_{n-1}\end{array}\right\}$

$\left(\begin{array}{ll}1 & 8\end{array}\right)$

ここで $\mathrm{f}\left(\mathrm{x}_{\mathrm{i}}, \mathrm{p}_{\mathrm{j}}\right)=\mathrm{f}_{\mathrm{i}}, \mathrm{p}\left(\mathrm{x}_{\mathrm{j}}\right)=\mathrm{p}_{\mathrm{j}}$ とおいた．解は $\mathrm{p}_{\mathrm{j}}^{\mathrm{k}+1}=\mathrm{p}_{\mathrm{j}}^{\mathrm{k}+} \Delta \mathrm{p}_{\mathrm{j}}$ $\mathrm{k}$ とし, 収束判定は

$$
\sum\left|\Delta p_{j}^{k}\right| / \sum\left|p_{j}^{k}\right| \leq \varepsilon
$$

\section{5. 結果と考察}

傾斜板と円板の境界条件は, 流体出入口で压力 $\mathrm{p}=\mathbf{0}$, 壁の 一方を速度 V で移動する. 傾斜板の入力值は, $\mathrm{l}=5 \mathrm{~mm}$, 分割 数 $25, \mathrm{~V}=5 \mathrm{~m} / \mathrm{s}, \mathrm{h}_{1}=2 \mu \mathrm{m}, \mathrm{h}_{2}=1 \mu \mathrm{m}$ で, 縦弾性係数 $\mathrm{E} \geqq$ $2 \times 10^{14} \mathrm{~Pa}, \kappa \geqq 0.1 \times 10^{-10} 1 / \mathrm{Pa}$, 収束条件 $\varepsilon \geqq 0.05$ とした. 収束状況はかなり峳しく, Reynolds の式の $\mathrm{h}^{3}, \mathrm{dp} / \mathrm{dx}(=0 \sim$ $10^{10} \mathrm{~Pa} / \mathrm{m}$ )が影響していると思われる. Fig.3 は, 傾斜板にお ける数值解の圧力分布とそのときの初期值(正解)を示す. 前 進差分で示す数值解では, P の彌係数が原因して流体出口付 近で，圧力突起が見られる．後退差分では，入り口付近でわ ずかに見える. 分割を細かくするとほぼ滑らかな曲線となり， 数値解でも圧力突起は見られない.

Fig.4 は，半径 $40 \mathrm{~mm}$ の円板に㵎滑油が膜厚さ $1 \mu \mathrm{m}$ で接 寸る場合で, 数値解は分割数が多いと解析解に一致する. 分 割数が少ないと, 図のように圧力曲線に乱れが出来る. Fig.5 は圧力による円板表面の変位を示す，正負圧部で円板は，そ れぞれ圧縮と膨張による変位を示している。

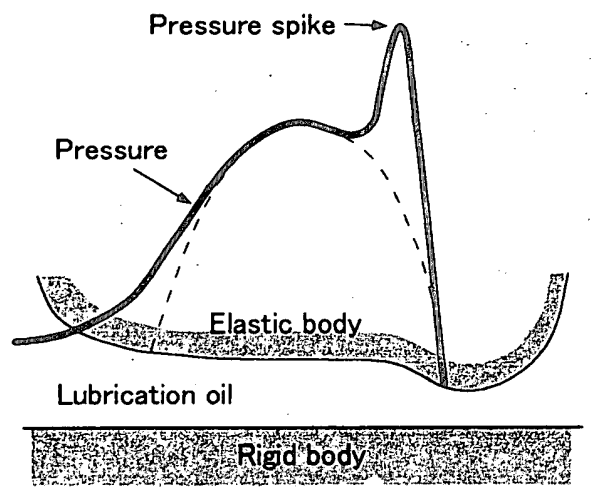

Fig.1 Pressure spike

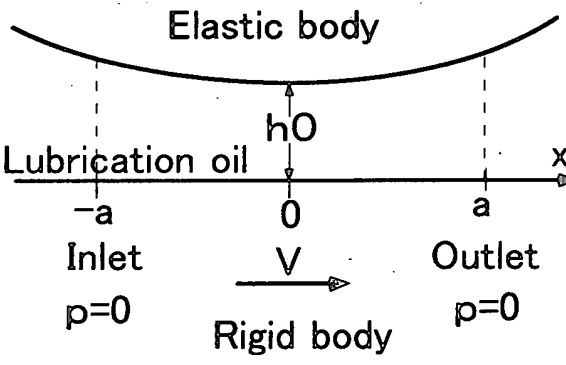

Fig.2 Disk model

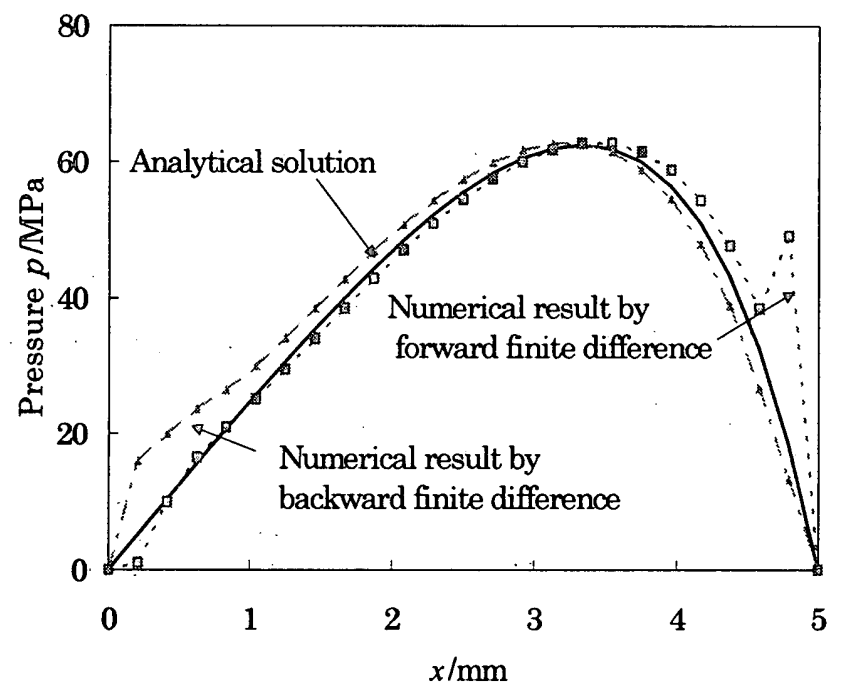

Fig.3 Pressure distributions of the slanted plate model

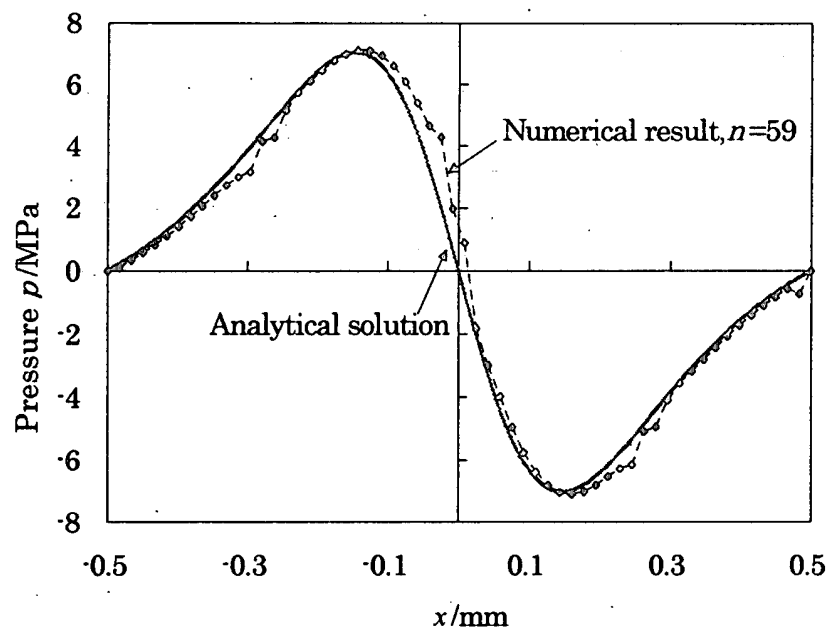

Fig.4 Pressure distributions of the disk model

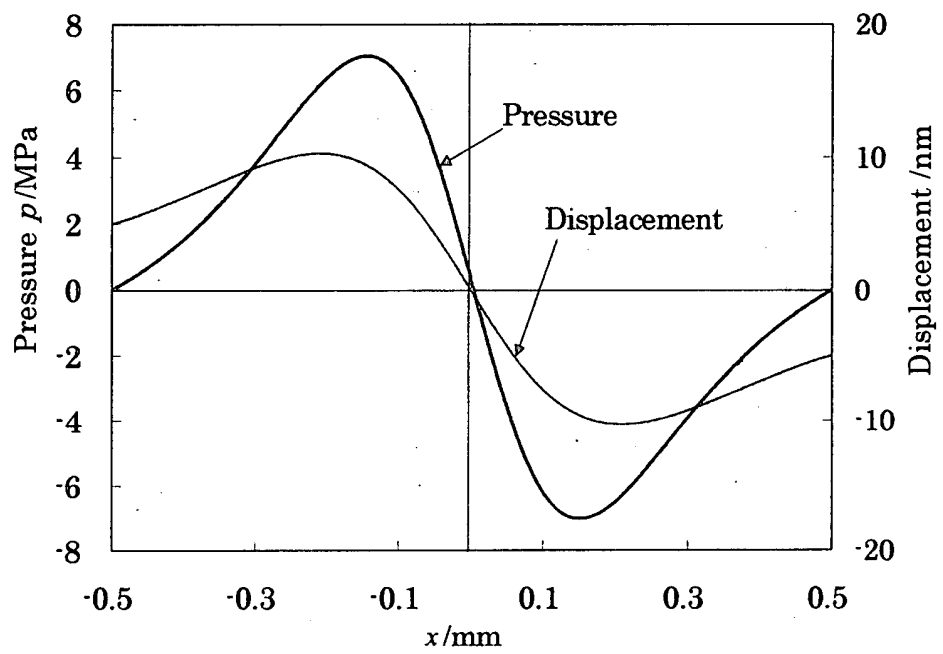

Fig.5 Displacement at the contact surface of the disk 